\title{
Supply-Side Structural Reform Related to the One-Stop Service of Beijing Sanlian Hope Shin-Gosen Technical Service Co., Ltd. (in Short for SLHP)
}

\author{
Chenggang Li \\ Institute of Fashion Technology, Business School of Beijing, Beijing, China \\ Email: ccid205@126.com
}

How to cite this paper: Li, C.G. (2018) Supply-Side Structural Reform Related to the One-Stop Service of Beijing Sanlian Hope Shin-Gosen Technical Service Co., Ltd. (in Short for SLHP). American Journal of Industrial and Business Management, 8 , 2288-2293.

https://doi.org/10.4236/ajibm.2018.812153

Received: November 9, 2018

Accepted: December 2, 2018

Published: December 5, 2018

Copyright $\odot 2018$ by author and Scientific Research Publishing Inc. This work is licensed under the Creative Commons Attribution International License (CC BY 4.0)

http://creativecommons.org/licenses/by/4.0/

\begin{abstract}
Supply can be divided into productive supply and commercial supply. The main reason for the supply-side structural reform is to enhance the productive forces, to solve the deep-rooted problems of the economic structure, to moderately control the expansion of supply and to adapt the development of demand by the flexible supply methods. Many innovative reforming modes and actual cases emerged during the supply-side reform of the upgrading and structural adjustment in the textile industries. In this article, based on the innovative application of one-stop service of SLHP, from the point of enterprise management innovation, the author comprehensively described the application and effectiveness of the supply-side structural reform in the textile industries.
\end{abstract}

\section{Keywords}

Supply-Side Structural Reform, One-Stop Service, Innovation

\section{Introduction}

The so-called "one-stop service" is that actually as long as customers have needs, once entering a service site, all the problems can be solved; there is no need to find a second one. In essence, it is system sales service. In the 21 century, with the development of the internet technology and informatization, in accordance with the demand of the competitive technology service market, a new form of technology service was formed and improved, which is one-stop service. As a new marketing model, by the simple and most effective processing, one-stop service increased the service quality and effectiveness, and increased the satisfac- 
tion rated of the service market. In a manner of speaking, one-stop service is a marketing innovation of the technology service market in the 21 century. Combining the industry development, SLHP innovatively designed and improved the one-stop service model of the Polyamide industry, which can be considered as the innovation business.

\section{Background of One-Stop Service Reform of SLHP}

\subsection{Objective Requirement of Supply-Side Structural Reform}

Supply-side structural reform was raised to solve the structural problems of the social society of China. Supply-side structural reform is to promote structural adjustment by means of reform, rectify distortions in factor allocation, expand effective supply, improve the adaptability and flexibility of supply structure to changes in demand, improve total factor productivity, better meet the needs of the broad masses of the people, and promote economic and social development, sustained and healthy development.

To fully grasp the essence of supply-side structural reform was very important for the directing the industry development and enterprises' reform.

First, the essential aim of supply-side structural reform is to increase the society production level, to implement the people-centred development thought. Namely, the supply-side structural reform required to moderately expand the overall demanding, at the same time, to cut excess capacity, to reduce inventory, to bring down the overall leverage ratio, to lower cost across the board, to strengthen the weak links in the economy, to strengthen the superior supplying in the production areas, to reduce the invalid supplying, to expand the valid supplying, to enhance the structure adaptability and flexibility, to increase the total factor productivity, to ensure the supplying system adapting with the changing of the demanding structure, all of which will facilitate to enhance the sustainable growth rate of the economy. So it required the industry to innovate the business model, to improve the productive management and service management level, to strengthen and create the increasing point of the industry development.

Second, the increasing mode changed from the pulling growth of the "three carriages" [1] to the intensive development of the elements effectiveness. In the supply-side structural reform, the innovation is the fourth element except labor force, land and the capital, which actualized the growth rate by the fully allocated of the four elements, namely the medium and long term potential economic growth rate. By adjusting the economic structure, the elements were mostly allocated to enhance the intensive development potential of the economy. All of these required the enterprises to create innovation environment, to improve the innovative forces.

Third, supply-side structural reform required to pay much attention on the moderation and accommodation of the demand, to moderately expand the overall demand... enhance the adaptability and flexibility of the supplying structure... promote the supplying system to adapt with the changing of the de- 
manding structure. All of these required the enterprises to adapt to the variety of market by model innovation.

\subsection{Potential Demand of the Development of the Polyamide Industry}

China's textile industry was seriously restricted by the foreign countries' technology \& market monopoly in many areas, which led to our textile industry in the bottom of the Smiling Curve. And without the advantages of in the advanced research \& development and brand channel, the related integration for the industry chain became very weak. Polyamide industry was the same as the textile industry, not only the technology, but also the products and market were in disadvantages. In the end of 20th century, the chemical fiber engineering technology service companies had realized the nationalized in the aspect of technology equipment, but they were weak in the production process, equipment manufacturing, technology optimized and engineering implementation, etc. Without the complete software technology packages, the overall technical collaboration mechanism cannot be formed, the level of the engineering equipment was hard to be effectively increased, all of which affected the product quality and the consistency of the production, and cannot meet the demand the rapid development of the industry.

In this background, SLHP created the one-stop service [2], with a team of about 70 people, it realized the net profit over 100 million in Year 2014 and landed on the Shenzhen Stock Exchange ChiNext Board. We need to learn more about the successful high efficient operation mode and management innovation from SLHP.

\section{Analysis on the Innovation Strategy of One-Stop Service of SLHP}

\subsection{Systemized Designing the One-Stop Service in the Polyamide Industry}

The one-stop service in the chemical fiber areas of SLHP mainly provided the core processing technologies in program designing, process designing, foundational designing, and detailed designing, also provided the overall services for the purchasing, production process, equipment manufacturing, technology optimizing, program starting, products guarantee and the after sales, etc, so to ensure the continuous improvement in the process technology and its special equipment. By these, it can form the efficiently interactive environment between marketing demand and technical improvement, to create the engineering service model with rich connotations and to promote the consistent promotion and value added.

\subsection{Flattened Enterprise Organization Structure Matching One-Stop Service Model}

In order to adapt with the one-stop service model SLHP adopted the flattened 
enterprise organization structure. In this organization structure, the chairman of the board and general manager directly managed both the functional and business departments, with short power distance, so the problems can be handled and solved highly and efficiently. At the same time, in this flatted enterprise organization structure, it required to downsize the staffs, also to required them in charge of more positions and more compound, such as, for the engineering technology staffs, they were required both the capacities in professional designing, and the capacities in job organization, field coordination, installation guidance, debugging, etc. In SLHP, one-stop service model required the purchasing, management and after-sales staffs with both the special knowledge and knowledge in processing, equipment and electric instrument. This flattened organization structure and staff requirement really had successfully support one-stop service of SLHP to show performance and to promote the highly effective operation of SLHP [3].

\subsection{Information Technology to Realize the One-Stop Service Model}

In the growth of the Internet Plus of China, the intellectualization in the production and service was an important part. With the advantages of the internet remote operation, for SLHP, by the same operational platform, professional staffs on site inputted the problems incurred in the fieldwork, to the self-constructed cloud computing system, so the engineers in Beijing Headquarters can analyze the problems and solve them. This model was rapid, networking, intellectualization and green, which greatly improved the effectiveness and quality of the service.

\subsection{Production-Study-Research System Supporting the Sustainable Development of One-Stop Service Model}

On the basis of technology, service as the output, with the advantages of the internet, one-stop engineering service model was a consistently improved and advanced system, which consistently improved the technical standard and quality level with the changing of the market demanding. The construction of the production-study-research system had provided good platform for the technology innovation, and industrialization. SLHP created a three-dimensional research \& development model, which is vertical and horizontal combination. Vertically, SLHP paid much attention on the changing of the technology in Polyamide areas, to utilize the cooperation platform with the colleges and scientific institutions, to analyze and discuss prospectively on the new technology, new products, new manufacturing process and new equipment in Polyamide industry; and at the same time, to carry out the special research on the specific problems incurred during the projects implementation, in order to find out the practical theoretical solutions. Horizontally, SLHP tried efforts to conduct closer cooperation with Polyamide producing enterprises, taking the marketing demand the technical trends of Polyamide industry into consideration, and combining the implementing projects, conducted research on the 
perspective areas, and conducted the practical test of the research and development achievement by the engineering transformation. SLHP had cooperated with many research institutions and colleges in Taiwan and domestic, to implement production-study-research system and got positive results. Also, by utilizing the three core technologies including cloud data digging [4], cloud credit computing and cloud structure service [5], SLHP integrated the textile industry resources and established the big data system of textile industry, conducted the operation and expansion in the platform of one-stop service model, conducted multi-dimensional service innovation in the finance, information and credit areas, established the new innovation service model supported by credit service and capital, to facilitate the sustainable development in the high-quality textile enterprises in China.

\section{Performance}

\subsection{Technical Par}

SLHP had obtained many autonomic intellectual properties, including invention patent, practical new-type patent and software copyrights. SLHP had participated to set the state standard once. Also SLHP had gained state rewards, provincial and ministerial rewards and undertook the state scientific programs.

\subsection{Economic Part}

In the late 3 years, SLHP got rapidly increasing in the economic benefits. In year 2014 , the operation revenue was about 420 million, increasing by $20.84 \%$, with net profit about 110 million, increasing by $35.99 \%$.

\subsection{Social Benefit Part}

By the special service model, SLHP had contributed lots on the overall service level for improving the Polyamide industry, to guide the technical equipment advantages and scientific results into practical productivity.

\section{Concluding Remarks}

In the face of the difficulties and problems of the industry, SLHP upheld the modern marketing ideas, innovated the service model, improved the one-stop service mode, which met the clients' demand, and at the same time, facilitated the development of the upstream industry chain; also SLHP integrated the overall industry chains by its own service platform and obtained practical achievements, and brought about demonstrative significance to the relevant enterprises which were practicing supply-side structural reform.

\section{Fund Project}

1) Beijing Municipal Education Commission's Social Science Program General Project-Research on the Dynamic Mechanism of Fashion Enterprise Innovation (AL2017-13); 
2) "Special fund for the construction of high-level teachers in Beijing Institute of Fashion Technology"-Beifu Scholars Program, project number: BIFTXZ201803;

3) The "2017 Light of Textiles" China Textile Industry Federation Higher Education Teaching Reform-innovation and entrepreneurship education into professional personnel training reform and practice of one of the results.

\section{Conflicts of Interest}

The author declares no conflicts of interest regarding the publication of this paper.

\section{References}

[1] Cui, J.-F., zhang, X. and Cui, W. (2014) Adjust the "Three Carriages" to Maintain Stable and Rapid Economic Growth. Journal of Shijiazhuang University of Economics, No. 4, 1-5.

[2] Zhong, W.J. (2018) From "One-Stop Shop" Administrative Approval to "No More than One Visit". Journal of Social Sciences Edition, 20, 69-74.

[3] China Textile Industry Enterprise Management Association (2016) Blue Book on Management Innovation Achievements of China's Textile Industry (2014-2015). China Textile Press, Beijing, 64-71.

[4] Wang, Z.G. and Wu, M. (2016) Improved Data Mining Method for Scattered Point Cloud Data in Distributed Environment. Journal of Xi an Polytechnic University, No. 5, 633-638.

[5] Jiang, F.C. (2014) Design of Infrastructure of Cloud Computing and Cloud Applications Services. Computer engineering \& Software, No. 7, 97-102. 